\title{
On the ideas of modern engineering
}

\author{
Huizhong Xue \\ Griffith University, Australia \\ xue.hz@live.cn
}

\begin{abstract}
Keywords: engineering; idea; harmonious; green engineering
\end{abstract}
Abstract. The engineering ideas, which reflect value pursuits of engineering practitioners, are overall, principled, programmatic requirements for engineering. From the function aspect, the engineering ideas are the fundamental guiding ideology as well as essential principles for engineering practices. Based on the predecessors' achievements, this paper presents that the core ideas of modern engineering can be summarized to have following attributes: people-oriented, resource saving, and environmental friendly. Furthermore, the relevant explanations and demonstrations to each point are incorporated.

\section{Introduction}

Creating a better living, working environment with more convenience for people is the major duty of engineering progress. To achieve such a great objective, engineering stakeholders should have appropriate engineering ideas in mind. Engineering ideas refer to the general engineering concepts: overall, principled, programmatic requirements for engineering. These ideas are the soul to lead engineering activities, and the basic principles to coordinate and settle various contradictions as well as conflicts. Therefore, the importance of having engineering ideas cannot be ignored. A number of scholars have discussed engineering ideas deeply ${ }^{[1-7]}$, based on which, this paper presents that the core ideas of modern engineering can be summarized to have following attributes: people-oriented, resource saving, and environmental friendly. Furthermore, the relevant explanations and demonstrations to each point are incorporated.

\section{People-Oriented}

All of the human activities should have one ultimate goal: obtaining happiness, so as the engineering activities. During engineering processes, human beings utilize the nature, change the nature, try to control the nature, and acquire natural resources for living. In addition, respecting nature, complying with nature, protecting nature, and seeking a harmonious relationship with nature are all for the people themselves. Therefore, the people-oriented concept should be regarded as the most essential engineering idea ${ }^{[1]}$.

What is the connotation of the people-oriented? Engineering activities serves people. It aims at satisfying people's reasonable needs and concerning about the healthy development of human society. As a result, promoting engineering development only for pure progressing or superficial prosperity should not be encouraged. In other words, even the most decent structures but without fulfilling people's reasonable needs cannot be viewed as people-oriented. This can be clearly revealed from public facilities construction. Putting satisfying people's needs at the first place is an expression of the people-oriented concept. For example, at the Paris airport, passengers are able to get transferred to automobiles or trains in the same building. Besides, safety control and noise control also reflect the people-oriented concept.

In recent decades, numbers of people have been criticizing the anthropocentrism as they hold that it should be responsible for the global resource and environmental crisis. Anthropocentrism can be interpreted from two aspects: 1. regarding people as the center of the universe or the ultimate purpose; 2. considering everything in the universe according to the human values. Anthropocentrism believes that having moral responsibility for the environment and the nature is mainly stemmed from people's concern about surviving, social development as well as the interests of next generations, i.e., we 
protect the nature because we want to protect ourselves. However, the criticizers argue that it is not enough for human beings to focus only on their own interests. Protecting animals, plants, and environments should also be embodied in that moral responsibility. In fact, anthropocentrism should not be blamed for the contemporary global crisis. The absolutism of the existence of nature only for human beings, the combining of the human greedy nature and the market economy development pattern, and the people's ignorance of consequences are the causes.

\section{Harmony between Engineering and Society}

Engineering constructions are not carried out in a pure natural environment. A complex social environment usually is involved, which may trigger social contradictions and conflicts and finally lead to social disharmony, for example, the migrants' issues in hydraulic engineering, the land expropriation problems in railway engineering, the living disturbance and environment pollution in construction engineering, the corruption in the engineering field, etc. Some large engineering activities may cause tensions between countries, regions, and areas, that is, water conservancy project for a river across different regions or countries. What is more, some engineering projects only take care of individual or a minority of people and ignore the interests of others, which may cause social disputes and damage social harmony.

The harmony between engineering and society mainly includes two aspects. The first aspect refers to the interpersonal harmony. One of the basic premise of happiness for people is living kindly together with others as human beings are social animals. Harmony between people and people, people and areas, regions and regions, or region and countries reflects the fair and justice principle. Accordingly, insisting on this principle is crucial to promote social harmony, which requires that everyone should be treated fairly instead of only focusing on the interests of parts of people. That is to say, during engineering activities, coordinating and balancing interests of each stakeholders should be paid more attention to. In particular, the project construction needs to consider the needs not only of the contemporary generation, but also of future generations to realize the intergenerational justice.

The second aspect refers to the harmony between engineering works and humanistic environment. Engineering works need to be harmonious with humanistic environment as they are in the latter. Mao states that, except for the unique practical function on which a bridge should be designed based, creating a harmony with surroundings is another thing that the engineers should consider

${ }^{[3]}$.According to this principle, there are numbers of failures of engineering constructions in China. For example, the government of Yingquan district of Fuyang city in Anhui province costly built a luxurious office building with a nickname "Fuyang White House". It forms extremely strong contrast to the outdated surroundings. A similar case happened in Gold Town of Zhongxian in Chongqing.

\section{Harmony between Engineering and Nature}

Human beings must be in harmony with nature. The reason supporting this fundamental is that human beings and the nature constitute the world. People can only live with and in the nature. The human existence strongly relies on the nature by acquiring natural resourced and environment. As a result, losing harmony with the nature can be disastrous for human beings. For a long time, people conduct engineering activities without considering the possible negative effect on the nature, which leads a rapid deterioration of quality of the ecology and the environment. Consequently, people should try to make full use of the nature and respect it at the same time.

So here comes the question: how to respect and adapt to the nature? Engineering activities have direct interaction with the nature. This means that they will disturb the nature, and conversely, be restricted by the nature. It seems that these activities can hardly comply with the nature, but use, conquer, control, change the nature, and finally turn it to an unnatural state. To human beings, the nature is remarkably powerful and sometimes unfriendly. When complying with the nature is discussed, this behavior is active and with people's conscious. This is the reason why people need to concede when they are trying to change the nature. However, on the other hand, overcome it while 
facing its threats. This is a state of harmony between those activities and the nature. Engineering helps people to challenge the nature, however, it cannot be denied that no engineering project can drag people completely free from the dependence on nature. If a conquering activity brings severe punishments, then it is an adaptable behave by no means. Numbers of engineering projects leading to revenges of the nature, which can be viewed as unsuccessful in the history. For a long time, the traditional concept of engineering put too much weight on conquering nature, technical updating, and utilitarian. Thereby, the respecting and protecting the nature are ignored.

Fortunately, human beings are animals who are able to consciously think and choose a way to adapt to the nature. Harmony with the nature is an appropriate thought turning into one of the core idea of modern engineering and one of the basic principles guiding engineering activities. The so-called harmony refers to a balanced state that engineering activities do not ruin the nature, and conversely, keep themselves unharmed from it. To go further, this principle can be manifested as following points.

Firstly, achieving engineering objectives under the natural laws is a form of complying with the nature. In fact, those natural laws are infrangible. Yet, under the premise of obeying those natural laws, still there are numbers of engineering decisions need to be made, such as choosing construction sites, choosing loads bearing systems, making structural arrangement, etc. From this point, engineering practitioners need to make changes in a feasible scope distanced from harming the nature to obtain engineering targets.

Secondly, engineering activities definitely disturb the normal functioning of the nature. Yet, these intervention activities have two sides: natural aspect and unnatural aspect. The principle needs to be followed is that try to conduct engineering activities from their natural aspect. For example, if a landscape beautification can be carried out with a conformity with the local natural terrain, by utilizing local natural flora, then it reflects its natural aspect. Contrastively, largely changing the local natural terrain and introducing flora that is incompatible with the local ones are unnatural engineering activities.

Thirdly, large engineering projects may bring negative effects to natural environments. The ecology system may be disturbed and get unbalanced if those effects are severe. The occurrence of this type of disaster obviously is not seen as making harmony with the nature. The point is that trying to protect environments and maintain a balanced ecology system is essential during the engineering processes. This implies that the harmony can be obtained if disasters and nature damages can be avoided while using and changing nature by engineering practices. Take the road construction for instance, assuring the function of vehicle traffic and trying to make as less environment changes as the engineers can to emerge the road into the landscape is a leading harmonious strategy.

Engineering objects are embedded in the nature, both must be harmonious ${ }^{[5]}$. Engineering in harmony with the natural environment is also the embodiment of the principle of nature and humanity. Mao Yisheng pointed out that the construction of Zhaozhou Bridge achieved the perfect combination with the surrounding natural environment, the idea got fully reflecting when he designed Qiantang River Bridge $^{[3]}$. Dujiangyan Project built more than two thousand years ago is another successful example of transform nature, the perfect crystallization of nature and human wisdom.

\section{Green Engineering}

In almost all living practice fields, modern people desire for the green color which represents life and vital ecosystem. From engineering perspective, the connotation of green mainly includes two points. The first one is resource saving, utilizing resources with high efficiency. The second one is treating environment friendly, attempting to avoid any ecosystem damage.

Take the green building as an example to illustrate the green engineering concept ${ }^{[4]}$. Recently, people sheds increasingly focus on social sustainable development. This type of development is able to satisfying the needs of contemporary generation without compromising the resource collection ability of future generations. The green idea can be associated with the sustainable development. In 
this context, the green building concept has been put forward, referring to those resource saving and environment-friendly buildings which deal with environmental and resource problems. The design of traditional buildings basically is guided by principles of comfort, safety, and convenience, paying more attention to practical functions, economical efficiency, and decent appearances. As a consequence, traditional buildings usually have some setbacks: more energy consumption, long construction cycle, and more construction waste. On the other hand, the green building concept gives more weight on resource saving and environment protecting. It acknowledges the building's environmental attributes at a same or even higher importance level than ones of other characteristics including: functions, quality, lifecycle, cost, etc. Therefore, it is able to solve pollution problems and save resources from the beginning. In China, the green building assessment code GB50378-2006 has been enforced for several years. This code points out some crucial requirements of being a green building: making a great effort to save resources, protect environments, and mitigate pollution; providing people healthy, suitable room for living and working with efficiency.

\section{Conclusion}

Engineering ideas are the basic principles managing the whole process of engineering activities. Therefore, they have a great significance for success of the engineering project. The modern engineering focuses on the people-oriented concept, the harmony between engineering and society, as well as the harmony between engineering and nature. Engineering aims at promoting a sustainable development of human society. To achieve this target, saving resources, consuming resources reasonably, and protecting environments are remarkably crucial. Therefore, the core ideas of modern engineering can be summarized as following points: people-oriented, resource saving and environmental friendly.

\section{References}

[1] Z.H. Fu: Journal of Zhejiang University(Humanities and Social Sciences) Vol. 37(3)(2007), p. 5(in Chinese)

[2] Q.Y. Shen, H.Q. Li: Science Technology and Engineering Vol. 5(21)(2005), p. 1634(in Chinese)

[3] Y.S. Mao: Mao Yisheng Selection (Beijing Press, Beijing 1996), p. 149 (in Chinese)

[4] K. Zhan: Sichuan Construction Science Research Vol. 36(5)(2010), p. 265 (in Chinese)

[5] Z.H. Miao, N. Bian, C.Z. Yang: Economics and management Vol. 26(12)(2012), p. 63 (in Chinese)

[6] Y.L. Wang, H.B. Wang: Studies in Dialectics Nature Vol. 21(9)(2005), p. 59(in Chinese)

[7] R.Y. Yin: China engineering science Vol. 10(3)(2008), p. 4 (in Chinese) 